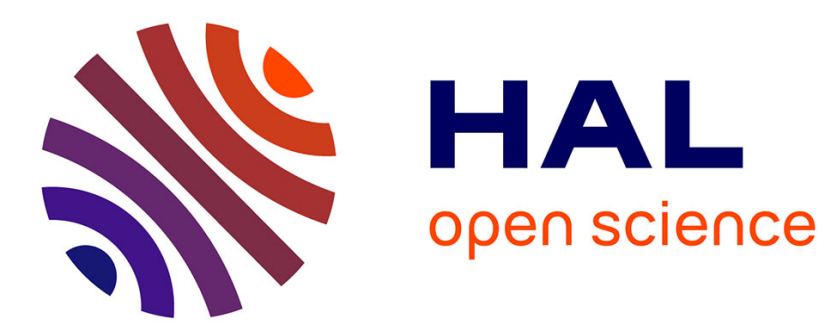

\title{
A Methodology for Optimal Semi-Active Suspension Systems Performance Evaluation
}

Charles Poussot-Vassal, Sergio Savaresi, Cristiano Spelta, Olivier Sename, Luc Dugard

\section{- To cite this version:}

Charles Poussot-Vassal, Sergio Savaresi, Cristiano Spelta, Olivier Sename, Luc Dugard. A Methodology for Optimal Semi-Active Suspension Systems Performance Evaluation. CDC 2010 - 49th IEEE Conference on Decision and Control, Dec 2010, Atlanta, Georgie, United States. pp.n.c. hal-00534732

\section{HAL Id: hal-00534732 \\ https://hal.science/hal-00534732}

Submitted on 10 Nov 2010

HAL is a multi-disciplinary open access archive for the deposit and dissemination of scientific research documents, whether they are published or not. The documents may come from teaching and research institutions in France or abroad, or from public or private research centers.
L'archive ouverte pluridisciplinaire HAL, est destinée au dépôt et à la diffusion de documents scientifiques de niveau recherche, publiés ou non, émanant des établissements d'enseignement et de recherche français ou étrangers, des laboratoires publics ou privés. 


\title{
A Methodology for Optimal Semi-Active Suspension Systems Performance Evaluation
}

\author{
C. Poussot-Vassal, S.M. Savaresi, C. Spelta, O. Sename and L. Dugard
}

\begin{abstract}
This paper concerns the study of the optimal performance computation of a semi-active suspension evaluated in terms of comfort and handling performances. To this aim the semi-active suspension system is described as a quartercar model, equipped with a controllable damper, providing an effective representation of the semi-active suspension dynamics. The passive suspension presents dual performances: at low frequency the better comfort performances are ensured by a high damped suspension, whereas the best comfort damping is low at mid and high frequency. The handling performance is perfectly the opposite. This study highlights how this trade-off can be overcome with an optimal control of damping and how the best performances in terms of comfort are reflected in terms of handling and vice verse. The main result of this paper is to propose a methodology allowing for evaluation of handling and comfort lower theoretical filtering bounds, which can be used as a benchmark for any semi-active control design.
\end{abstract}

\section{INTRODUCTION}

\section{A. Motivations and framework}

Among the many different types of controlled suspension systems (see e.g. [1], [2], [3], [4], [5], [6], [7], [8], [9]), semi-active suspensions have received a lot of attention since they seem to provide the best compromise between cost (energy-consumption, actuators/sensors hardware) and performance. The concept of semi-active suspensions can be applied over a wide range of application domains: roadvehicle, cabin in trucks or tractors, seat, trains, appliances (e.g. washing machines), architectural (buildings, bridges, etc.), bio-mechanical structures (e.g. artificial legs) etc. (see e.g. [10], [11], [12], [13], [14], [15], [16], [17], [18], [19], [20], [21]).

The research in this field follows two mainstreams: the study of new technologies of semi-active actuation of damping (like electro-hydraulic, electro-rheological and magnetorheological damper), and the design of semi-active control strategy. The results presented here are in between these streams, and more specifically, focusses on the performance analysis.

In this applicative domain (as well as in any engineering domain), it is very useful and convenient to evaluate what

C. Poussot-Vassal is with the Systems Control and Flight Dynamics Department (DCSD) of ONERA, 2 Avenue Edouard Belin, BP 74025, 31055 Toulouse Cedex, FRANCE.

S.M. Savaresi is with the Dipartimento di Elettronica e Informazione, Politecnico di Milano, Piazza L. da Vinci 32, 20133 Milano ITALY (e-mail: savaresi@elet.polimi.it).

C. Spelta is with the Dipartimento di Ingegneria dell'Informazione e Metodi Matematici, Universitá degli Studi di Bergamo, viale Marconi 5, 24044 Dalmine (BG) ITALY (e-mail: cristiano.spelta@unibg.it).

O. Sename and L. Dugard are with the Department of Control Systems of the GIPSA-lab, Grenoble INP, FRANCE (e-mail: olivier.sename@gipsalab.grenoble-inp.fr; luc.dugard@gipsa-lab.grenoble-inp.fr). are the best performances a given system can achieve if all the necessary information is available and no computation limitations exist. This "optimal bounds" are very important when evaluating a control design since it allows the designer to measure how far the controlled systems (designed on realistic limitations and simplifications) is from the best achievable performances.

\section{B. Contribution and structure}

This paper focusses on the analysis of the optimal performances of a semi-active suspension in terms of handling and comfort. Recently a study of the performance limits of a semi-active suspension system has been presented [3], mainly focused on the comfort objective. This paper aims at providing a full analysis of the optimal performances both for the comfort and for the handling objectives. Further this work presents a comparative study of the relationship between these two objectives.

Due to the complexity and the nonlinear phenomena composing the semi-active suspension systems, these optimal performances cannot be analytically calculated but approximated through a numerical optimisation approach, grounded on Model Predictive Control (MPC, see e.g. [22], [23]). Thus, the main result of the paper is so to provide a methodology allowing for building a useful benchmark to the designers of semi-active control algorithms.

This work is carried out on the basis of a quarter-car description of the suspension system and the performances are evaluated both in the time and in the frequency domain.

The paper is organized as follows: Section II presents the semi-active suspension problem statement and models. In Section III, the optimisation task is presented, as rooted in the Hybrid MPC framework. Numerical results are discussed in Section IV, illustrating then the efficiency of the proposed methodology. Finally, Section V concludes the paper.

\section{SEMI-ACTIVE SUSPENSION PROBLEM STATEMENT}

\section{A. Nonlinear model description}

The semi-active suspension system can be described according to the following quarter-car model:

$$
\left\{\begin{aligned}
M \ddot{z} & =-k\left(z-z_{t}-\Delta_{s}\right)-c\left(\dot{z}-\dot{z}_{t}\right)-M g \\
m \ddot{z}_{t} & =k\left(z-z_{t}-\Delta_{s}\right)+c\left(\dot{z}-\dot{z}_{t}\right) \\
& -k_{t}\left(z_{t}-z_{r}-\Delta_{t}\right)-m g \\
\dot{c} & =-\beta\left(c-c_{i n}\right) \\
z_{t}-z_{r} & <\Delta_{t}
\end{aligned}\right.
$$

where $z, z_{t}$, and $z_{r}$ are the vertical positions of the body, of the unsprung mass, and of the road profile respectively. 
$M$ is the quarter-car body mass; $\mathrm{m}$ is the unsprung mass (tire, wheel, brake calliper, suspension links, etc.). $k$ and $k_{t}$ are the stiffness of the suspension spring and of the tire respectively; $\Delta_{s}$ and $\Delta_{t}$ are the length of the unloaded suspension spring and tire, respectively. $c$ and $c_{i n}$ are the actual and the requested damping coefficients of the shockabsorber, respectively. The damping-coefficient variation is ruled by a 1 st-order dynamic, where $\beta$ is the bandwidth. The actual damping coefficient $c$ always remains in that interval: $0 \leq c_{\min } \leq c \leq c_{\max }$, where $c_{\min }$ and $c_{\max }$ are the shockabsorber technological limitations. This last limitation is the so-called "passivity-constraint" of a semi-active suspension - guaranteeing that the actuator only dissipates energy [9], [4], [5]. Since the control signal $c_{i n}$ modifies the damping coefficient $c$, a state variable, the model (1) is nonlinear.

In the case of a passive suspension with a constant damping coefficient, (1) is reduced to a 4th-order linear system (by simply setting $\dot{c}=0$ and $c=$ constant - e.g. nominal damping).

\section{B. Linear model with passivity-constraint description}

An other way to define the semi-active quarter-car model, more tractable for our purpose, is given as follows:

$$
\left\{\begin{aligned}
M \ddot{z} & =-k\left(z-z_{t}\right)-c^{0}\left(\dot{z}-\dot{z}_{t}\right)-F_{d} \\
m \ddot{z}_{t} & =k\left(z-z_{t}\right)+c^{0}\left(\dot{z}-\dot{z}_{t}\right)-k_{t}\left(z_{t}-z_{r}\right)+F_{d} \\
\dot{F}_{d} & =-\beta\left(F_{d}-u\right)
\end{aligned}\right.
$$

With reference to model (1), the linearised model (2) includes symbols with the following meaning. $c^{0}$ denotes the nominal damping set as $c^{0}=\left(c_{\min }+c_{\max }\right) / 2 ; F_{d}$ is an additional damping force commanded by the control variable $u$, according to a 1 st order actuation dynamic.

Note that in order to be fully equivalent to (1) the control signal $u$ should respect the passivity-constrain. In model (1) this constraint is described as $c_{\min } \leq c_{i n} \leq c_{\max }$. It is easy to see that in model (2) this constraint is recast as follows: the additional force reference $u$ should satisfies $u \in \mathcal{D}\left(c_{\text {min }}, c_{\text {max }}, c^{0}\right) \subseteq \mathbb{R}$, where the dissipative $\mathcal{D}\left(c_{\min }, c_{\max }, c^{0}\right)$ set is defined as follows (see also Figure $1)$ :

$$
\left\{\begin{array}{c}
\forall(U, V) \in \mathbb{R} \times \mathbb{R} \mid \\
\left(U-\left(c_{\text {max }}-c^{0}\right) V\right)\left(\left(c_{\text {min }}-c^{0}\right) V-U\right) \geq 0
\end{array}\right\}
$$

where $c_{\min }$ and $c_{\max }$ are the minimal and maximal damping factor of the considered controlled damper, normalized around $c^{0}=\left(c_{\max }-c_{\min }\right) / 2$. Note that in formulation (2) of the quarter-car model, the system with no control $(u=0)$ is damped thanks to $c^{0}$ (hence stable - without badly damped modes). This remark is practically crucial, and will make the system more tractable by a numerical optimisation.

Now, it is possible to define (2) in the LTI state-space form. To this aim consider the following state-space vector $X$ and input vector $W$ :

$$
\begin{aligned}
& X=\left[\begin{array}{lllll}
\dot{z} & z & \dot{z}_{t} & z_{t} & F_{d}
\end{array}\right]^{T} \\
& W=\left[\begin{array}{ll}
z_{r} & u
\end{array}\right]^{T}
\end{aligned}
$$

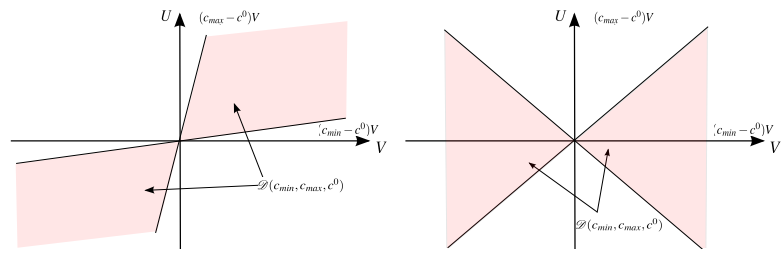

Fig. 1. Illustration of the dissipative $\mathcal{D}\left(c_{\min }, c_{\max }, c^{0}\right)$ set as a function of $c^{0}$. Left: $c^{0}=0$, right: $c^{0}=\frac{c_{\min }+c_{\max }}{2}$.

Then, model (2) can be written as:

$$
\Sigma_{c}\left(c^{0}\right): \dot{X}=A\left(c^{0}\right) X+B W
$$

For our purpose, and in order to describe the optimisation problem, model (2) is defined in the discrete-time domain (through backward Euler method with a sampling time $T_{e}$ ). The resulting discrete-time model $\Sigma_{d}\left(c^{0}\right)$ is given by:

$$
\Sigma_{d}\left(c^{0}\right): X(k+1)=\left(I+A\left(c^{0}\right)\right) T_{e} X(k)+B T_{e} W(k)
$$

where $A \in \mathbb{R}^{5 \times 5}$ and $B \in \mathbb{R}^{5 \times 2}$ are the dynamic and the input matrix of the system, respectively.

\section{Performance definitions}

Since the goal of the paper is to evaluate the performance trade-off of the semi-active suspension system in terms of comfort and handling, performance criteria have to be clearly defined. For this purpose, focus is given on two specific signals (indeed transfer), representing either the comfort or the handling performance (for further detail, refer to [18], [24] and book of the authors [5], to appear), namely:

- The vertical chassis acceleration $\ddot{z}$ (or displacement $z$ ) response to road disturbances $z_{r}$, between 0 and $20 \mathrm{~Hz}$, representing the acceleration felt by the driver, i.e. the comfort specification.

- The vertical wheel deflection $z_{t}-z_{r}$ response to road disturbances $z_{r}$, between 0 and $30 \mathrm{~Hz}$, representing the ability of the wheel to stay in contact with the road, i.e. the handling specification.

The common objective is then to minimize either the transfer $z_{r}$ to $\ddot{z}$ - identically $z$ - (comfort) or the transfer $z_{r}$ to $z_{t}-z_{r}$ (handling) or a combination of these two transfer. In the following section, this problem is formally described.

\section{MAIN RESUlt: OPTIMAL SEMI-ACTIVE PERFORMANCE COMPUTATION}

Since the semi-active quarter-car model presents actuator limitations which may be viewed as variable saturations, the method consists in describing a nonlinear optimisation problem with the following elements (indeed the problem will be defined as a mixed-integer optimisation one, to take the advantage to recent optimisation tools - [25], [26]):

- A cost function, representing the performance objectives, either comfort or handling, to be minimized (described in III-A). 
- A quarter-car model (given in discrete-time), which represents the dynamical equality constraints of the optimisation problem (described in III-B).

- A set of logical control inequality constraints guaranteeing the passivity-constraint of the actuator. These constraints are specific for the semi-active application and they will be described with binary variables in the optimisation problem (see III-C).

Additionally, since the aim of this work is to evaluate the optimal theoretical performances a semi-active suspension system can achieve, the following assumptions are made:

- The measure of the road disturbance $z_{r}$ is considered as known for a given time horizon consisting of $N$ samples, namely, $Z_{r}(k)=\left[z_{r}(k) z_{r}\left(k T_{e}\right), \ldots z_{r}(k(N-\right.$ 1) $\left.T_{e}\right)$ ], is known.

- The variables $z, z_{t}$ and $z_{r}$ are measurable.

- The system model is perfectly known.

On Figure 2, the general iterative optimisation scheme to compute the optimal comfort and handling bounds is shown, gathering the previous objectives and hypotheses.

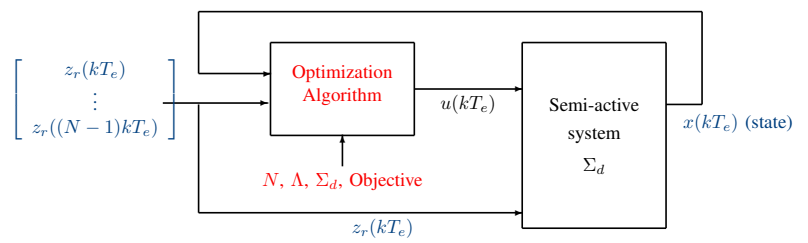

Fig. 2. Computation scheme of the semi-active suspension optimal performance.

On Figure 2 the "Optimisation Algorithm" takes as input the state measure $x\left(k T_{e}\right)$ and the present and future of road disturbance collected in vector $Z_{r}$. In the following, cost functions, equality and inequality constraints are described, and then, finally, the complete optimisation problem is given in Section III-D.

\section{A. Cost (objective) functions}

The aim of a suspension system in a vehicle is to filter the road disturbances to the body (comfort perspective), without deteriorating the road-tire contact forces (handling perspective). To properly define these objective, let define the following cost functions (defined through $\mathcal{L}_{2}$ metrics):

- The comfort cost function (see e.g. [18], [24]):

$$
J_{c}(N)=\sum_{k=0}^{N-1}(\ddot{z}(k))^{2}
$$

which measures the vertical acceleration of the suspended mass $M$ over $N$ samples.

- The handling cost function (see e.g. [18], [24]):

$$
J_{h}(N)=\sum_{k=0}^{N-1}\left(z_{t}(k)-z_{r}(k)\right)^{2}
$$

which measures the vertical tire deflection $z_{t}(k)-z_{r}(k)$ over $N$ samples.

\section{B. System equality constraints}

The equality constraints of the optimisation problem are gathered in the dynamical system definition. Here, let consider $\Sigma_{d}\left(c^{0}\right)$ (with $c^{0}=\left(c_{\min }+c_{\max }\right) / 2$ ), the discrete-time semi-active quarter-car model defined in (6), as the equality constraint set.

\section{Actuator inequality constraints}

Similarly the optimisation inequality constraints are contained in the passivity-constraint definition. Theses (logical) inequality constraints aims at guaranteeing the fact that the control signal lies in the dissipative $\mathcal{D}\left(c_{\min }, c_{\max }, c^{0}\right)$ domain.

Let define $\Lambda$, the set of logic constraints, containing binary variables, ensuring that the control signal $(u)$ lies in domain $\mathcal{D}\left(c_{\min }, c_{\max }, c^{0}\right)$, as:

$$
\text { if } \dot{z}-\dot{z}_{t} \geq 0, \Lambda: \quad\left\{\begin{array} { l } 
{ u \geq ( c _ { \operatorname { m i n } } - c ^ { 0 } ) ( \dot { z } - \dot { z } _ { t } ) } \\
{ u \leq ( c _ { \operatorname { m a x } } - c ^ { 0 } ) ( \dot { z } - \dot { z } _ { t } ) } \\
{ \text { if } \dot { z } - \dot { z } _ { t } < 0 , \Lambda : }
\end{array} \left\{\begin{array}{l}
u \leq\left(c_{\min }-c^{0}\right)\left(\dot{z}-\dot{z}_{t}\right) \\
u \geq\left(c_{\max }-c^{0}\right)\left(\dot{z}-\dot{z}_{t}\right)
\end{array}\right.\right.
$$

where $\dot{z}-\dot{z}_{t}$ is the suspension deflection velocity, $\left(c_{\text {min }}-\right.$ $\left.c^{0}\right)$ (resp. $\left.\left(c_{\max }-c^{0}\right)\right)$ is the new minimal (resp. maximal) allowable damping ratio of the considered nominally damped discrete-time quarter-car model.

Behind this constrain definition, it clearly appears that the control signal is dependent on the state value, and especially, on the state sign. Therefore, the $\Lambda$ constraints involve binary variable. This peculiarity makes the problem non trivial; as a matter of fact, the optimisation problem became a mixedinteger optimisation problem.

\section{Optimisation problem definition}

Following the previous definitions, and under Figure 2 perspective, the following MPC optimisation problem may be defined:

$$
\begin{aligned}
& J_{i}^{*}(N)=\min _{u} J_{i}(N) \\
& \text { s.t. }\left\{\begin{array}{lll}
X(0) & = & X(k) \\
X(k+1) & = & (6) \\
\Lambda & = & (9)
\end{array}\right.
\end{aligned}
$$

where $J_{i}$ is the criteria to be minimized over the time horizon consisting of $N$ samples, $\Lambda$ is the set of inequality logical constraints and $X(k+1)$ are the dynamical equality constraints initialized by $X(0)=X(k)$, the state measure at the given iteration. The problem may be solved either for the comfort index (7) or for the handling index (8).

Since this problem is linear and involves logical constraints, it can be iteratively solved by using the YALMIP parser [26] together with GLPK general optimisation solver [25]. In conclusion, note that the optimisation problem (10) depends on a structural parameter corresponding to the time horizon $N$. 


\section{NUMERICAL DISCUSSION}

To explore the semi-active suspension performances, problem (10) has been solved for the comfort and handling cost functions with the following set of parameters (representing a motorcycle system): $M=117 \mathrm{Kg} ; m=30 \mathrm{Kg} ; k=26 \mathrm{kN} / \mathrm{m}$; $k_{t}=250 \mathrm{kN} / \mathrm{m} ; c_{\min }=900 \mathrm{Ns} / \mathrm{m} ; c_{\max }=4300 \mathrm{Ns} / \mathrm{m}$; $\beta=50.2 \pi \mathrm{rad} / \mathrm{s}$ and finally $T_{e}=1 \mathrm{~ms}$.

For evaluation purposes the results are illustrated in the frequency domain by the means of the approximate frequency response (FR). In fact, since system (5) is non linear, the idea of frequency response cannot be used in this domain. However it is possible to provide an approximation according to the following procedure [5]:

Algorithm 1 Nonlinear Frequency Response Computation To compute the approximate Frequency Response of $F_{z}(f)$ - comfort characteristic - and $F_{z_{\text {deft }}}(f)$ - handling characteristic - of a (controlled) nonlinear suspension systems the following procedure is computed:

1) A sinusoidal road disturbance $z_{r}(t)$ feeds the input of the nonlinear quarter vehicle models, over $P$ periods such that:

$$
z_{r}(t)=A \sin (2 \pi f t)
$$

where $A \in\left[\begin{array}{ll}1 & 5\end{array}\right] \mathrm{cm}, f \in[f \bar{f}] \subseteq\left[\begin{array}{ll}1 & 30\end{array}\right] \mathrm{Hz}$ and $t \in$ $[P / \bar{f} P / \underline{f}] \mathrm{s}$, where $\{P \in \overline{\mathbb{N} \mid} P>1\}$ is the number of periods of the sinusoid feeding the system. Practically one may choose $P=15$.

2) The output signals $y(t)$ are measured. Here, $y(t)=$ $z(t)$ (vertical suspended mass displacement) and $z_{\text {def } f_{t}}(t)=z_{t}(t)-z_{r}(t)$ (tire deflection).

3) For each signal the corresponding spectrum $Y(f)$ of $y(t)$ (and $U(f)$ of $z_{r}(t)$ ) is computed (by mean of a discrete Fourier Transform).

4) The power spectral density of $Y(f)$ and $U(f)$ signals are computed; denoted as $G_{y}(f)$ and $G_{u}(f)$.

5) For each output signal of interest, the Variance Gain is computed as: $F(f)=G_{y}(f) / G_{u}(f)$. In our case, $F_{z}(f)$ and $F_{z_{\text {deft }}}(f)$ signals are obtained.

Note that the above procedure has much in common with the concept of describing function (see e.g. [12]). Further for linear systems this corresponds to the numerical computation of the exact frequency response.

\section{A. Comfort optimal performances}

In Figure 3, the results for the comfort optimisation are reported. For benchmarking the results are compared with the suspension performances with minimum or maximum level of damping. Figure 3 reports also the results sensitivity to the optimisation horizon parameter $N$.

In terms of comfort (Figure 3 - top) there exist two resonances (clearly visible for low damping). A first body resonance around $2 \mathrm{~Hz}$ and a wheel resonance around $13 \mathrm{~Hz}$. These two resonance are shown also in the handling approximate FR (Figure 3 - bottom).

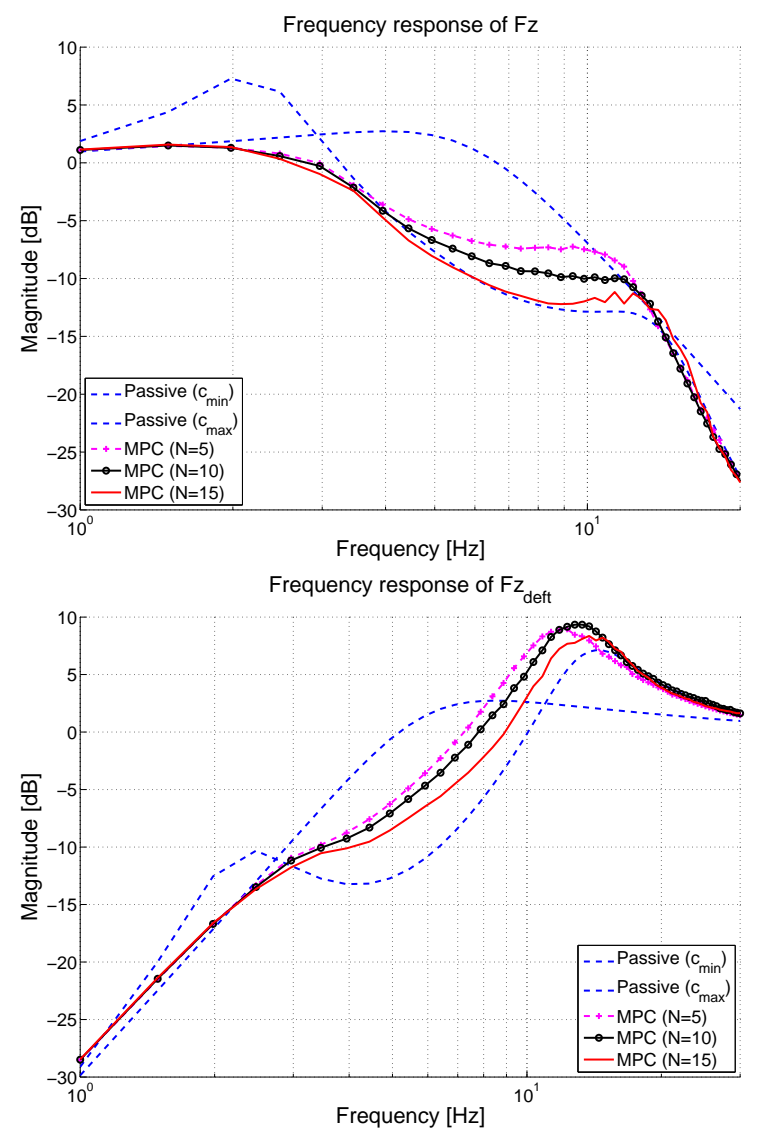

Fig. 3. Results of the comfort-oriented optimisation (i.e. cost function $J_{c}$ ) with varying prediction horizon $N$. Top: approximate FR from the road vertical acceleration to the body vertical acceleration. Bottom: approximate FR from the road profile to the tire deflection.

- The comfort passive trade-off between minimum damping $\left(c_{\min }\right)$ and maximum damping $\left(c_{\max }\right)$ is evident (Figure 3 - top). At low frequency a high damped suspension provides a good damping of the body resonance, but a bad filter of mid and high frequencies. On the other hand a low damping ensures a good filtering but a badly damped body resonance. Around $3 \mathrm{~Hz}$ there is the so called damping invariant point [5]. At this frequency the filtering performance are independent on the damping. Any passive setting is a compromise between high and low damping.

- The handling passive trade-off has an opposite flavour (Figure 3 - bottom). The high damping guarantees the best results in terms of tire deflection around the body and the wheel resonance. However at mid frequencies a low damped suspension provides better results. Also in this situation any passive setting represents a compromise between a over and under damped suspension.

- The optimal comfort response is able to outperform the passive settings at every frequency (Figure 3 top). Interestingly enough it seems to inherit the "best behaviour" of $c_{\min }$ at mid-high frequencies, and of $c_{\max }$ at low frequencies. It is worth noticing also that 
the optimal control of the damper is able to remove the limitation of the damping invariant point.

- The optimal comfort response provide performances comparable with a low damped suspension in terms of handling (Figure 3 - bottom). Note that, in these terms, the best of comfort is achievable without a deterioration of the handling performances (apart from the wheel resonance, where a little degradation occurs).

- The sensitivity analysis of $N$ is also reported in Figure 3. Note that, as excepted, the larger the better. In particular the sensitivity seems to be more critical around the wheel resonance, where the time horizon turns to be comparable to the suspension dynamics.

- In high frequencies (above $10 \mathrm{~Hz}$ ), the FR of $F_{z}$ appears to be not so well attenuated, and quite chattering. This is mainly due to the FR computation. Anyway, it does not affect our analysis since amplifications are very small.

\section{B. Handling optimal performances}

The handling counterpart of this analysis is reported in Figure 4, which reports the results of optimisation problem (10) for the handling cost function (8). From Figure 4 some considerations can be drawn:

- The handling optimal response is able to remove the passive trade-off almost completely. It behaves at a mid damped suspension at low frequency, like a low damped suspension at mid frequencies and like a over-damped suspension around the wheel resonance.

- The optimal handling control provides the best results in terms of handling without a degradation of the performances in terms of comfort. Note that the best handling performances are comparable with a low damped suspension in terms of comfort.

- The sensitivity analysis confirms the above results of the comfort optimisation.

- Similarly to the above comfort case, in very low frequencies, the optimisation does not seems to optimally operate, but since it concern very low amplitude, the FR of $F_{z_{\text {deft }}}$ does not affect the result in a significant manner.

Concluding the analysis, note that there exist a compromise between the best-handling and the best-comfort. These tow performance indexes cannot be optimized simultaneously.

\section{Performance indexes and comfort/handling trade-off}

Let define the function $\mathcal{C}: \mathbb{R} \times \mathbb{R} \times \mathbb{R} \rightarrow \mathbb{R}$, as $\mathcal{C}(X, \underline{f}, \bar{f})=\int_{f}^{\bar{f}}|x(f)|^{2} d f$, where $x(f)$ represents the frequency dependent signal of interest, obtained with the FR Algorithm 1; $\underline{f}$ and $\bar{f}$ represent the interval limits of interest. Then, the comfort and handling criteria are respectively defined as:

- $J_{z}$, Comfort criteria:

$$
J_{z}=\frac{\mathcal{C}\left(F_{z}, 0,20\right)}{\mathcal{C}\left(F_{z}^{\text {nom }}, 0,20\right)}
$$

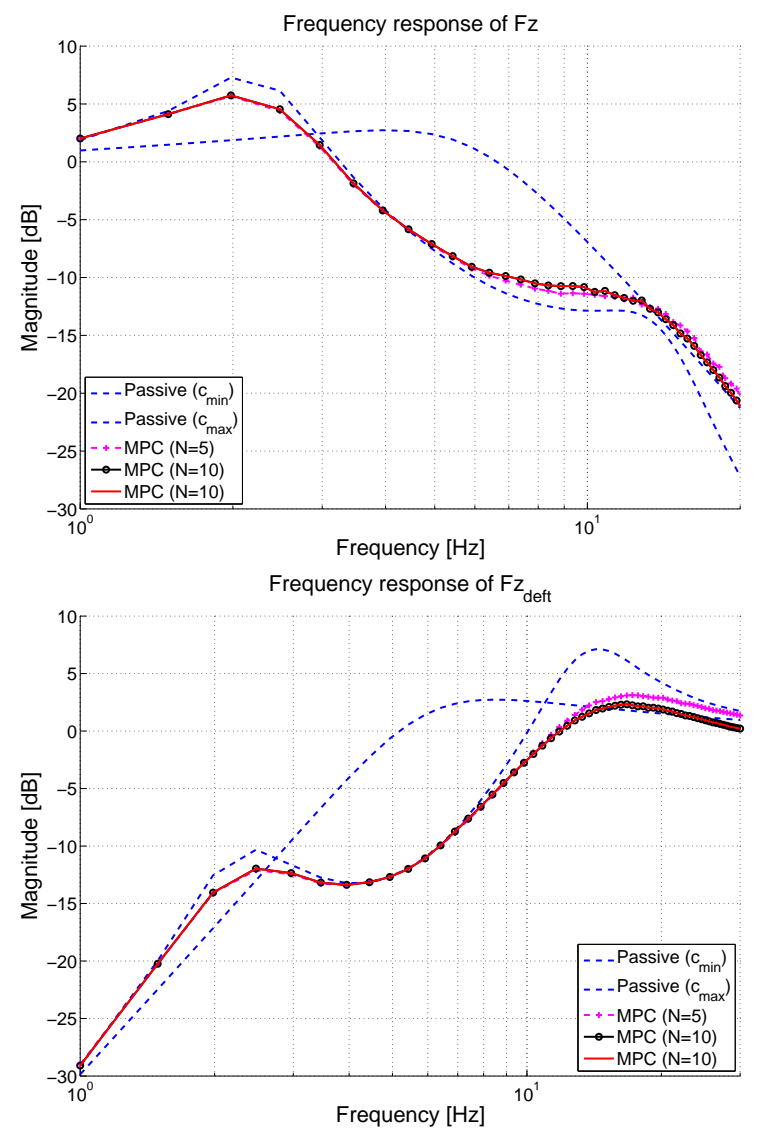

Fig. 4. Results of the handling-oriented optimisation (i.e. cost function $J_{h}$ ) with varying prediction horizon $N$. Top: approximate FR from the road vertical acceleration to the body vertical acceleration. Bottom: approximate FR from the road profile to the tire deflection.

- $J_{z_{\text {deft }}}$, Road-holding criteria:

$$
J_{z_{\text {def }}}=\frac{\mathcal{C}\left(F_{z_{\text {deft }}}, 0,30\right)}{\mathcal{C}\left(F_{z_{\text {deft }}}^{\text {nom }}, 0,30\right)}
$$

where $F_{z}$ and $F_{z_{\text {deft }}}$ are the FR obtained with Algorithm 1, and with the optimisation scheme; while $F_{z}^{\text {nom }}$ and $F_{z_{\text {def }}}^{\text {nom }}$ are the FR of the passive uncontrolled reference suspension gains obtained by Algorithm 1 as well, with $c^{0}$ nominal damping.

The numerical computation of indexes (12) and (13) are reported in Figure 5. These results confirm, concisely, the one shown in the above analysis.

In the continuity, to evaluate the trade-off between the comfort and the handling optimal bound the following cost function is herein introduced (with $\alpha \in\left[\begin{array}{ll}0 & 1\end{array}\right]$ ):

$$
J_{\alpha}(N)=\alpha J_{c}(N)+(1-\alpha) J_{h}(N)
$$

Problem (10) is then solved for the optimisation index (14). Note that index (14) is a convex combination of the comfort index (7) and the handling index (8). In Figure 6 the optimisation task is solved for several values of $\alpha$ and the results are depicted in the comfort-handling plane. For 


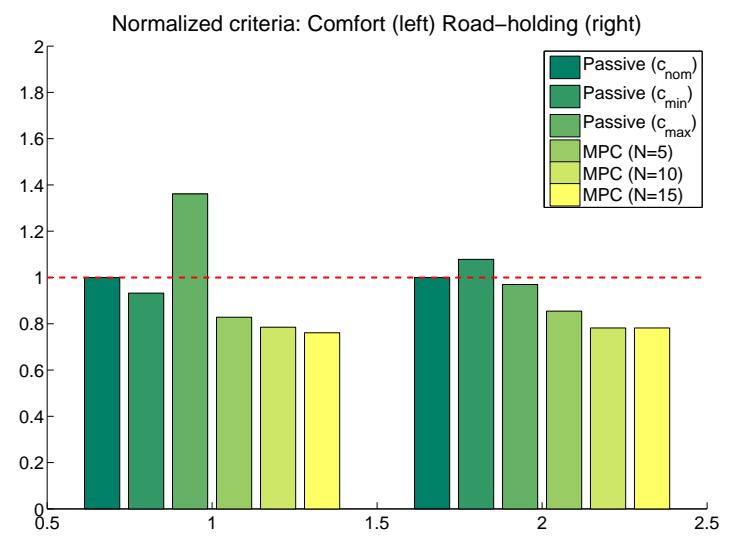

Fig. 5. Performance criteria (normalized with respect to nominal damping $c=c^{0}$ ). Optimal performance with respect to the prediction horizon $N$, compared to the passive settings. Left: comfort optimisation. Right: handling optimisation.

comparison, also a representation of the passive trade-off is depicted (i.e. with varying damping value).

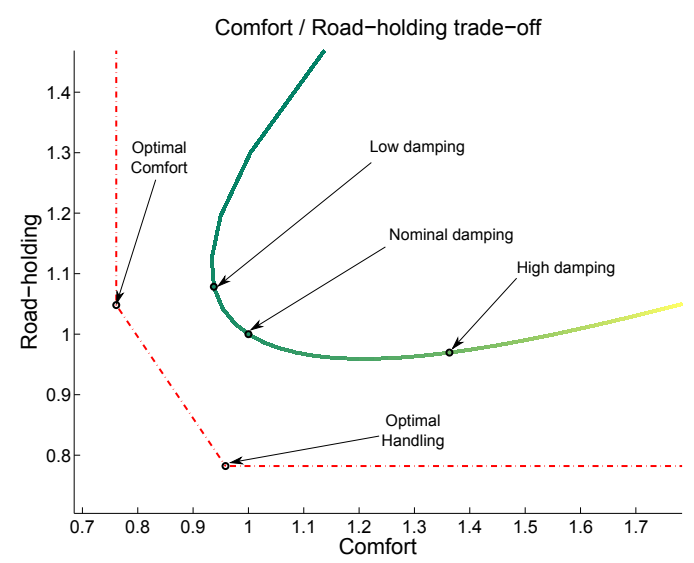

Fig. 6. Comfort-Handling plane $\left(\left\{J_{z}, J_{z_{\text {def }}}\right\}\right.$ trade-off) for a passive suspension system, with damping value $c \in\left[\begin{array}{lll}c_{\min } & c_{\max }\end{array}\right]$ (solid line with varying color) and optimal comfort / handling bounds, with $\alpha \in\left[\begin{array}{ll}0 & 1\end{array}\right]$ (red dash dotted).

Note that, for any value of the convex parameter $\alpha$ an optimally controlled suspension outperforms a passive suspension for any fixed damping value in terms of the performance index (14). This provides an interesting picture of the potential benefits guarantee by the use of a semi-active suspension.

Figure 6 also highlights how any control of the damping parameter $c$ may be viewed as a compromise between the best handling and the best comfort.

To conclude this numerical analysis a time domain evaluation is also presented. Specifically the system is excited with a triangular $100 \mathrm{~ms}$ impulse of amplitude $6 \mathrm{~cm}$ (bump profile). Then the optimisation problem is solved for both the comfort and handling indexes. The results are depicted in Figure 7, and compared to the system equipped with a nominal damping $c=c^{0}$. Some conclusions can be done:

- The vertical body acceleration reveals that the comfortoriented suspension is able to have a relatively smaller values and it ensures a quicker settling time. Furthermore it avoids the obnoxious peaks given by the handling-oriented optimal suspension.

- The handling-oriented optimal suspension shows a deflection signal that is in general relatively smaller. Further it shows a very fast settling time. Interestingly enough, the comfort-oriented suspension is comparable to the handling-oriented suspension in the first part of the transient. However the comfort-oriented suspension suffers from relatively large movements of the tire deflection, that are exploited for a better filtering of the vibrations.
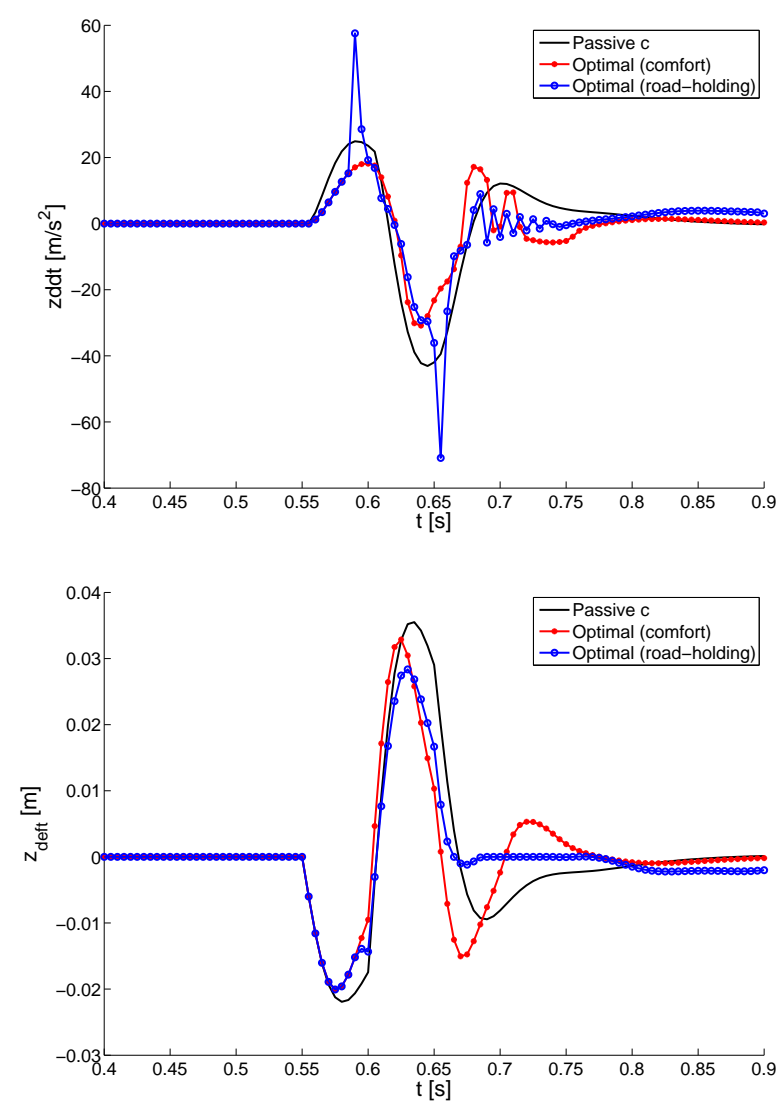

Fig. 7. Bump test responses of the optimal comfort-oriented control (solid small round red), optimal handling-oriented (solid large round blue) and Passive with nominal damping value (solid black). From top to bottom: chassis displacement $(z)$, chassis acceleration $(\ddot{z})$ and tire deflection $\left(z_{\text {deft }}\right)$.

\section{CONCLUSIONS}

This paper has been devoted to the presentation of a methodology allowing for a comparative analysis of the performance limits of a semi-active suspension, both in terms of handling and comfort. To this aim the suspension is modelled as the well-known quarter-car system and an optimisation problem is defined, based on the theory of 
Model Predictive Control, and using recent efficient tools from the Mixed Integer Programming. In order to study the performance limits ideally assumption have been done: the computational capability of the control system is assumed to be unlimited and the road disturbance is assumed to be known in advance. The main interest of the presented results of this paper is the definition of a methodology, useful for benchmarking any of semi-active control algorithms with respect to the best performance. Note that the interest of the method is that it can be extended to more complex suspension models, including more specific nonlinearities according to the employed technology.

\section{REFERENCES}

[1] M. Campi, A. Lecchini, and S. Savaresi, "An application of the Virtual Reference Feedback Tuning (VRFT) to a benchmark active suspension system," European Journal of Control, vol. 9, no. 1, pp. 66-76, 2003.

[2] D. Sammier, O. Sename, and L. Dugard, "Skyhook and $\mathcal{H}_{\infty}$ control of active vehicle suspensions: some practical aspects," Vehicle System Dynamics, vol. 39, no. 4, pp. 279-308, April 2003.

[3] S. Savaresi and C. Spelta, "Mixed Sky-Hook and ADD: Approaching the Filtering Limits of a Semi-Active Suspension," ASME Transactions: Journal of Dynamic Systems, Measurement and Control, vol. 129, no. 4, pp. 382-392, 2007.

[4] —_, "A single-sensor control strategy for semi-active suspensions," IEEE Transaction on Control System Technology, vol. 17, no. 1, pp. 143-152, January 2009.

[5] S. Savaresi, C. Poussot-Vassal, C. Spelta, O. Sename, and L. Dugard, Semi-Active Suspension Control for Vehicles. Elsevier (to appear), 2010.

[6] H. Tseng and J. Hedrick, "Semi-Active Control Laws - Optimal and Sub-Optimal," Vehicle System Dynamics, vol. 23, no. 1, pp. 545-569, 1994.

[7] M. Valasek, W. Kortum, Z. Sika, L. Magdolen, and O. Vaculin, "Development of semi-active road-friendly truck suspensions," Control Engineering Practice, vol. 6, no. 6, pp. 735-744, June 1998.

[8] R. Williams, Automotive Active Suspensions Part 1: basic principles, 1997, vol. 211.

[9] C. Poussot-Vassal, O. Sename, L. Dugard, P. Gáspár, Z. Szabó, and J. Bokor, "A New Semi-active Suspension Control Strategy Through LPV Technique," Control Engineering Practice, vol. 16, no. 12, pp. 1519-1534, December 2008.

[10] M. Ahmadian and B. Reichert, "System Nonlinearities Induced by Skyhook Dampers," Shock and Vibration, vol. 8, no. 2, pp. 95-104, 2001.

[11] R. Caponetto, O. Diamante, G. Fargione, A. Risitano, and D. Tringali, "A soft computing approach to Fuzzy Sky-Hook control of semi-active suspension,” IEEE Transaction on Control System Technology, vol. 11, no. 6, pp. 786-798, 2003.

[12] A. Gelb and W. V. der Velde, Multiple-Input Describing Functions and Nonlinear System Design, N. Y. McGraw-Hill, Ed., 1968.

[13] A. Giua, M. Melas, C. Seatzu, and G. Usai, "Design of a Predictive Semiactive Suspension System," Vehicle System Dynamics, vol. 41, no. 4, pp. 277-300, April 2004.

[14] R. Goodall and W. Kortüm, "Mechatronic developments for railway vehicles of the future," Control Engineering Practice, vol. 10, no. 8, pp. 887-898, 2002.

[15] P. Geurts, D. Ernst, and L. Wehenkel, "Extremely randomized trees," Machine Learning, vol. 63, no. 1, pp. 3-42, 2006.

[16] N. Giorgetti, A. Bemporad, H. Tseng, and D. Hrovat, "Hybrid Model Predictive Control Application Toward Optimal Semi-active Suspension," International Journal of Control, vol. 79, no. 5, pp. 521-533, May 2006.

[17] G. Guardabassi and S. Savaresi, "Approximate Linearization via Feedback - an Overview," Automatica, vol. 27, no. 1, pp. 1-15, 2001.

[18] D. Hrovat, "Survey of advanced suspension developments and related optimal control application," Automatica, vol. 33, no. 10, pp. 17811817, October 1997.

[19] D. Karnopp, M. Crosby, and R. Harwood, "Vibration Control Using Semi-Active Force Generators," Journal of Engineering for Industry, vol. 96, pp. 619-626, 1974.
[20] T. Kawabe, O. Isobe, Y. Watanabe, S. Hanba, and Y. Miyasato, "New semi-active suspension controller design using quasi-linearization and frequency shaping," Control Engineering Practice, vol. 6, no. 10, pp. 1183-1191, 1998

[21] W. Liao and D. Wang, "Semiactive Vibration Control of Train Suspension Systems via Magnetorheological Dampers," Journal of Intelligent Material Systems and Structures, vol. 14, no. 3, pp. 161-172, 2003.

[22] A. Bemporad, M. Morari, V. Dua, and E. Pistikopoulos, "The explicit linear quadratic regulator for constrained systems," Automatica, vol. 38, no. 1, pp. 3-20, January 2003.

[23] A. Bemporad, F. Borrelli, and M. Morari, "Min-Max control of constrained uncertain discrete-time linear systems," IEEE Transaction on Automatic Control, vol. 48, no. 9, pp. 1600-1606, September 2003.

[24] U. Kiencke and L. Nielsen, Automotive Control Systems. SpringerVerlag, 2000.

[25] “GLPK - GNU Linear Programming Kit," 2009. [Online]. Available: http://www.gnu.org/software/glpk/

[26] J. Lofberg, "YALMIP : A Toolbox for Modeling and Optimization in MATLAB," in Proceedings of the CACSD Conference, Taipei, Taiwan, 2004. [Online]. Available: http://control.ee.ethz.ch/ joloef/yalmip.php 